\title{
INTRACAPSULAR CATARACT EXTRACTION USING LOW TEMPERATURE*
}

\author{
BY \\ T. GWILYM DAVIES \\ London

\section{Preliminary Report}

THE first report on the use of cryosurgery in cataract extraction was made by Krwawicz (1961); since then he has reported 660 extractions performed by this method. Kelman and Cooper (1963) have described its use in an unspecified number of cases which included subluxated lenses and dislocated lenses. Bellows (1964) reported 6 cases. Rosengren (1965) gave the results of 120 cryoextractions. Experimental use of low temperature in ophthalmology was made by Scholar (1935) in producing an adhesive chorioretinitis in rabbits by the application of carbondioxide snow to the sclera. Bietti (1933) measured the fall in temperature at varying distances within the eye when dry ice and alcohol were applied to the sclera. Clinical use was made of the procedure in 1935 by Deutschmann, when he successfully produced an adhesive chorioretinitis in a case of retinal detachment.

\section{Method}

In this series the cryoextractor (Fig. 1) and method used are as described by Krwawicz. The operative technique is the same as that used for conventional extractions as far as incision and iridectomy are concerned. An assistant lifts the corneal flap while the operator, using a squint hook, exerts pressure at the junction of the middle and lower thirds of the cornea, causing the upper pole of the lens to come forward into the wound. If a complete iridectomy has been done it is possible to apply the cryoextractor to the lens at the

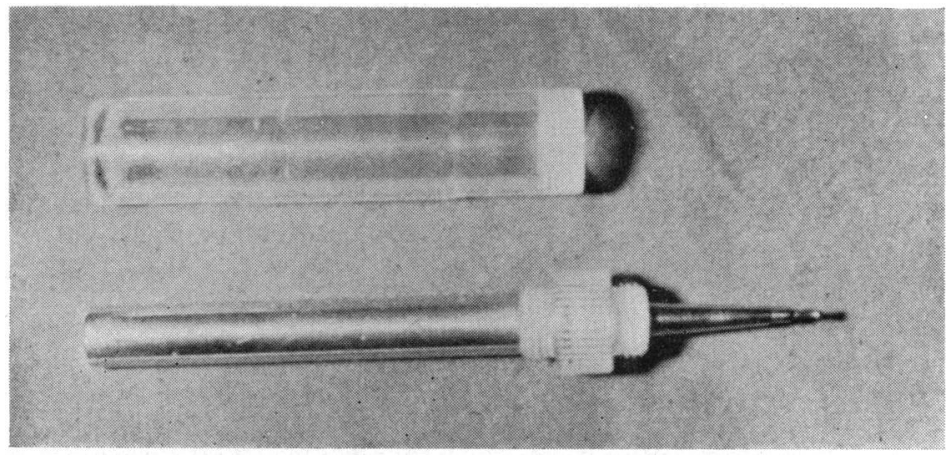

FIg. 1.-Cryoextractor with plastic cover. 


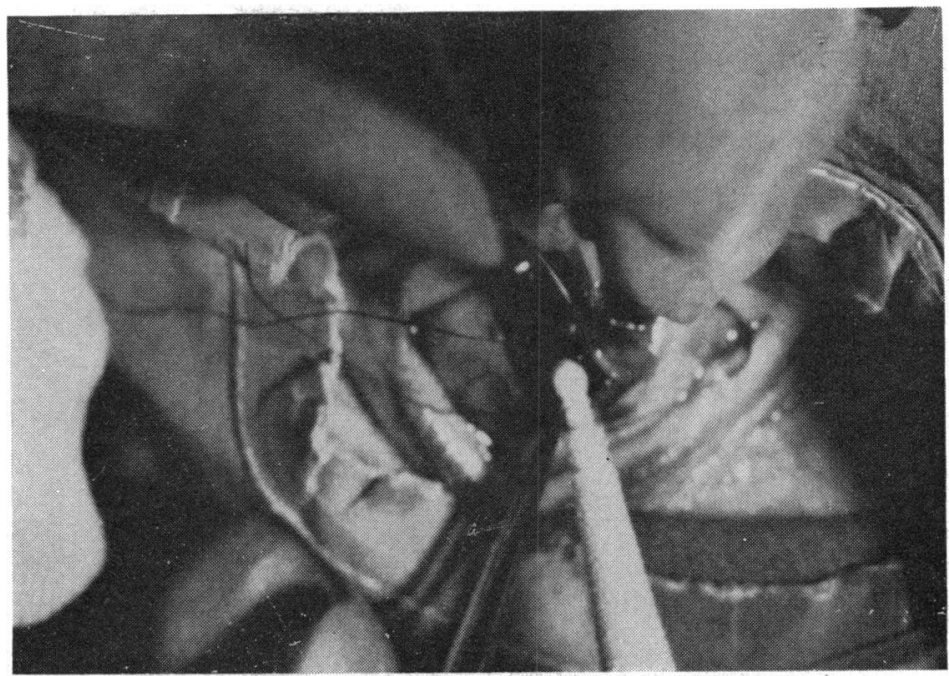

FIG. 2.-Cryoextractor applied and frozen to lens. Note forceps retracting iris and corneal flap being held back.

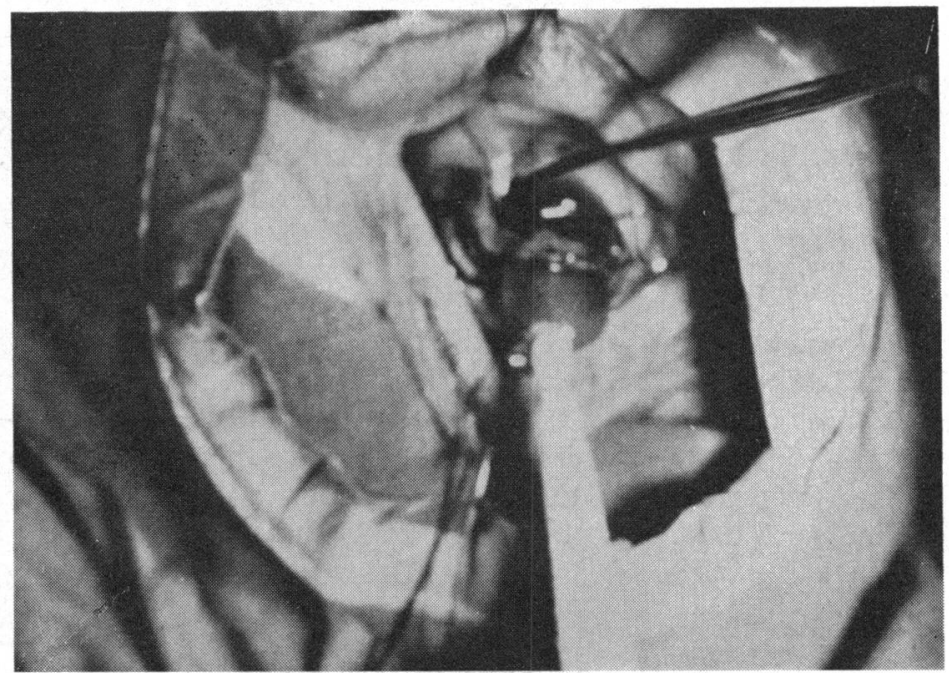

FIG. 3.-Extraction nearly completed with squint hook tucking cornea below lens.

12-o'clock position near the equator, with little danger of it adhering to the neighbouring tissues. When a peripheral iridectomy is done the iris is retracted upwards by the assistant to expose the upper pole of the lens (Fig. 2). This is done with a blunt hook or nontoothed iris forceps grasping the edge of the pupil at the 12-o'clock position. While constant pressure is being applied to the cornea with the squint hook, the cryoextractor, with the lens firmly adhering to it, is gently moved from side to side in order to rupture the zonule. As the lens becomes freer the side-to-side movements are increased and at the same time the lens is lifted into the wound. The delivery of the lens is assisted by the action of the squint hook tucking the cornea in behind the lower pole of the lens as it is being lifted out of the wound (Fig. 3). When the lens is extracted the cornea is swept across below it closing the wound (Fig. 4). 


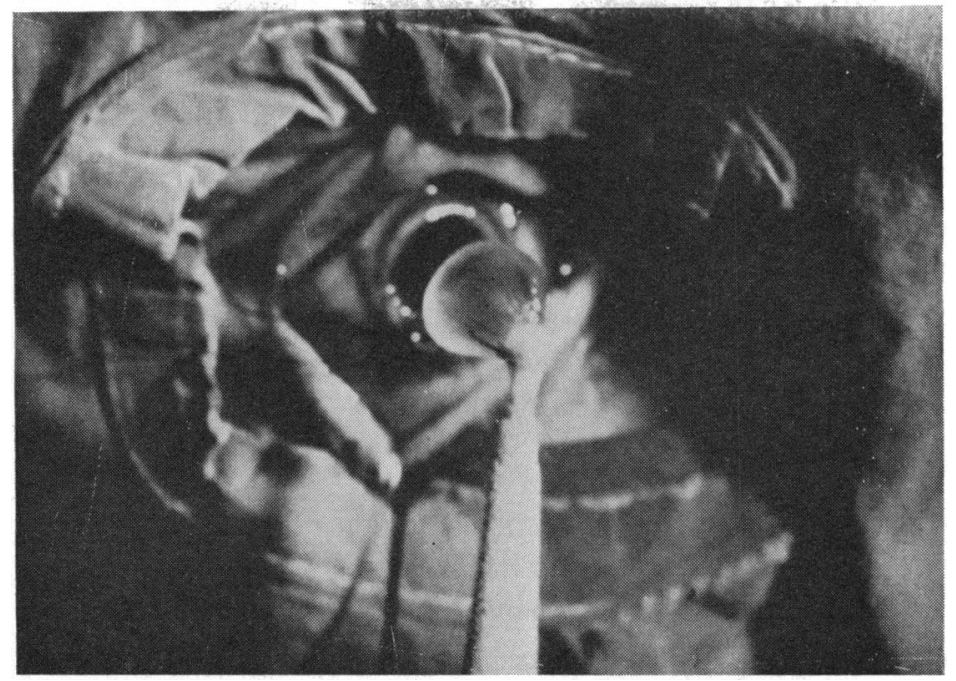

FIG. 4.-Extraction completed showing lens adhering to the cryoextractor.

\section{Results}

There was no selection of cases and 25 extractions have been performed. There were 23 intracapsular extractions and 2 were extracapsular. In none of the 25 cases was Zonulysin used. Operative complications were encountered in three cases:

Case No. 2.-The iris and cornea became adherent to the probe. The cornea was separated with no ill effects. Part of the iris was excised, producing a large iridectomy. There was vitreous loss and the capsule ruptured. Final result was satisfactory with visual acuity 6/9.

Case No. 3.-Adherence of cornea to the probe; easily separated with no ill effects.

Case No. 10.-Rupture of capsule occurred unexpectedly during straightforward extraction.

This method of cataract extraction requires that the corneal flap be lifted to about $60^{\circ}$. Any immediate post-operative damage to the corneal endothelium was particularly looked for. In 16 cases the cornea was perfectly clear; in 8 cases mild endothelial striae, as is often seen following forceps extraction, were noted; in one case marked endothelial opacification was present and had not completely cleared three months later, although visual acuity was $5 / 12$.

\section{Discussion}

When the temperature of a tissue is lowered below its freezing point it solidifies. The freezing point of any tissue depends on the water content of the tissue. Kelman and Cooper (1963), using a cryogenic system originally devised for thalamic surgeryconsisting of a cannula with a circulation of liquid nitrogen and the degree of coldness at the tip being controllable-found that the lens capsule became adherent to the tip when the temperature was $-5^{\circ} \mathrm{C}$. With further lowering of the temperature an increasing amount of the underlying lens matter becomes frozen. They also found 
that a lens suspended from a cryosurgical cannula can support a weight of $250 \mathrm{~g}$., whereas a lens suspended from an Arruga forceps ruptured when subjected to a weight of above $7.5 \mathrm{~g}$. It is because the cryoextractor has a firm grip on the lens that Krwawicz (1963) claims his method reduces the risk of accidental rupture of the capsule. In 660 cases that he has reported he had a 2 per cent. incidence of capsule rupture. In this present series there were 2 cases of capsule rupture. One case was at the beginning of the series when the iris and cornea had adhered to the probe, and the failure was due to faulty technique. In the other case there was no apparent fault in the technique and it must be included as a failure of the cryosurgical method.

Two cases of hypermature Morgagnian-type cataracts were operated on. These probably would have been difficult to remove intracapsularly, but they froze firmly to the cryoextractor and were extracted easily.

One case of endothelial damage occurred which may have been caused by lifting the corneal flap. However, it was the first case in this series and no similar damage has since been seen. Accidental freezing of the cornea occurred on two occasions and resulted in no permanent damage.

It is felt that this method has certain advantages over the conventional forceps method. Hypermature cataracts and immature cataracts in the swelling stage are often difficult or impossible to grasp with forceps, whereas their intracapsular extraction by cryosurgery is much more certain. Cryoextraction in these selected cases would seem advisable. When used routinely for all cataract operations there may be a statistical decrease in accidental capsule rupture. The danger of the probe becoming adherent to neighbouring tissues is a very real one, especially when one is first learning the technique. Adherence to the cornea or sclera is not serious and can easily be separated, but the delicate tissue of the iris may be torn and has to be excised.

\section{Summary}

A review of cryosurgery in ophthalmology is given. Cryoextraction after Krwawicz's method is described, and of the 25 cryoextractions performed, 23 were intracapsular, with accidental capsule rupture in 2 cases. The advantages of removing hypermature and intumescent cataracts by this method and the reduced risk of accidental capsule rupture are discussed. The disadvantages of accidental adherence to other ocular tissues, particularly the iris, are mentioned.

I am grateful to Professor T. Krwawicz for personal communications and for the gift of his cryoextractor. I also wish to thank Mr. M. Klein for allowing this series of operations to be performed on his patients and for his encouragement and valuable criticism in the preparation of this paper. I also thank Dr. H. Ho for taking the photographs.

\section{REFERENCES}

Bellows, J. G. (1964). Amer. J. Ophthal., 57, 29.

BietTI, G. (1933). Boll. Oculist., 12, 1427.

Deutschmann, R. (1935). Klin. Mbl. Augenheilk., 94, 349.

Kelman, C. D., and Cooper, I. S. (1963). Amer. J. Ophthal., 56, 731.

KrWAWICZ, T. (1961). Brit. J. Ophthal., 45, 279.

- (1963). Ibid., 47, 36.

Rosengren (1965). Trans. ophthal. Soc. U.K., in the press.

Scholar, F. (1935). Klin. Mbl. Augenheilk., 94, 349. 